REVIEW ARTICLE

\title{
Toxin producing freshwater cyanobacteria of Sri Lanka
}

\author{
S. A. Kulasooriya ${ }^{1,2, *}$ \\ ${ }^{I}$ Department of Botany, University of Peradeniya, Peradeniya, Sri Lanka \\ ${ }^{2}$ National Institute of Fundamental Studies, Kandy, Sri Lanka
}

\begin{abstract}
Cyanobacteria are photosynthetic, prokaryotic microorganisms commonly found among the phytoplankton of stagnant waters. Some of them produce toxins and these have been implicated to contribute to environmental health problems including kidney disease of uncertain etiology. This paper is a review of published literature on freshwater cyanobacteria of Sri Lanka with special emphasis on toxigenic genera. It is evident that the freshwater cyanobacterial populations of Sri Lanka have undergone significant changes from the beginning of the $20^{\text {th }}$ century until recent times. While toxigenic genera such as Microcystis and Cylindrospermopsis have been observed occasionally during the early $20^{\text {th }}$ century they have now become dominant in most of our waters except in those whose catchment areas are protected forests devoid of human habitation. Eutrophication through nutrient loading and other sources of pollution by anthropogenic activities triggers off cyanobacterial bloom formation which is an environmental health hazard. Minimizing pollution of lentic water bodies by the reduction of the use of chemical fertilizer and other agro-chemicals, restoration of riparian vegetation, biomanipulation to control cyanobacterial populations and breakdown of cyanotoxins through chemical, physical and microbiological methods have been proposed for the amelioration of this hazard. Extensive research studies on such aspects are warranted to develop solutions to overcome this environmental problem.
\end{abstract}

Keywords: cyanotoxins, algal blooms, CKDu, environmental health, water pollution.

\section{INTRODUCTION}

One of the primary goals of the World Health Organization (WHO) and its member states (including Sri Lanka) is to ensure that all people irrespective of their social and economic development have access to an adequate supply of safe drinking water. The National Water Supply and Drainage Board (NWSDB) is the organization entrusted with the responsibility of supplying safe drinking water to the public in Sri Lanka. It uses resources such as rivers, and irrigation tanks (reservoirs) as sources for their water supply schemes to both urban and rural populations. Such raw water is subjected to a general purification process the major steps of which include aeration, flocculation after coagulation with alum, sedimentation, sand filtration and chlorination. The water thus purified is routinely tested for physical features such as taste, color, odor, $\mathrm{pH}$, electrical conductivity and biological parameters like the presence of total and fecal coliform bacteria. These analyses are done to maintain standards set by the WHO to ensure that the water supplied for drinking purposesis safe and pure. However, these routine tests do not include the determination of heavy metals and cyanobacterial toxins that are currently being implicated in several environmental health problems such as chronic kidney disease of uncertain etiology (CKDu) and certain types of cancers (Dharmawardana, 2013; Jayatilake et al., 2013; Jeyakumaran, 2013 and Dissanayake, 2015). Due to the rapid increase of noncommunicable, environmental health problems (some of which are reaching epidemic proportions), a review of the diverse factors that contribute to the spread of such health issues is urgently warranted. One such area for review is toxigenic cyanobacteria in Sri Lanka.

Cyanobacteria are prokaryotic, photosynthetic, gram negative, organisms, ubiquitous in their global distribution and exhibit the widest morphological diversity among the Prokaryota (Kulasooriya, 2011). Some of the cyanobacterial genera produce toxins which are harmful and sometimes lethal to animals and man. Some of these toxins are thermo stable and cannot be destroyed by boiling, a common 
practice adopted to make drinking water safe. Review articles on cyanobacterial toxins and their potential impacts on animals and humans have been published by Carmichael (1992), Codd and Poon (1988) and more recently by Liyanage et al. (2016a).Although cyanobacterial toxins are traditionally identified as hepatotoxins, neurotoxins, dermatotoxins and saxitoxins, nephrotoxic effects have also been induced in experimental rats injected with cyanobacterial microcystins (Bhattacharya et al., 1997; Rymuszka and Sieroslawaska, 2009).More recently cyanobacterial toxins have also been implicated among the factors contributing to CKDu in Sri Lanka (Dissanayake, 2015; Liyanage et al., 2016b). Therefore the presence of toxigenic cyanobacteria in fresh water bodies of Sri Lanka and their occasional bloom formation are of serious concern. This article is an attempt to review most of the available information on these organisms in Sri Lanka.

OCCURRENCE: A CHRONOLOGICAL PERSPECTIVE IN THE 2OTH CENTURY

Scientific records on the occurrence of freshwater algae in Sri Lanka can be traced back to the early $20^{\text {th }}$ century. West and West (1902) have described 30 species of algae belonging to 18 genera under 6 families found in water samples collected from Anuradhapura, Hakgala, Hanwella, Henarathgoda, Kandy, Kekunandera, Kosgoda, Matara, Panadura, Peradeniya, Tibbotuwa, Uragasmanhandiya and Yadagamuwa. Fifty samples of algae collected from different localities by Mr. W. G. Freeman FLS, from the island of Ceylon in 1896 - 97 were examined by West and West to prepare this paper in which a few species of cyanobacteria have been described under the family Cyanophyceae (blue-green algae). The internationally well-known British algologist Prof. F. E. Fritsch has visited Sri Lanka and stayed for $2 \frac{1}{2}$ months from August to November 1903.During this period he has traveled along three routes.1) Along the coastline examining sub-aerial algae and phytoplankton of the estuaries and lagoons of Negombo, Panadura, Kalutara, Bentota, Ambalangoda and Matara. 2) To the northern plains up to Vavuniya and Trincomale eduring which he has paid special attention to the phytoplankton algae of the numerous irrigation reservoirs of the North Central and Eastern Provinces. 3) He has also paid a brief visit to Numwara Eliya and stayed several times at Peradeniya. In two classical research papers published in the Royal Society London (1907a) and Annals of Botany London (1907b), he has provided extensive information on the occurrence of algae including cyanobacteria in our freshwater bodies. According to these reports the tanks of the North Central Province such as Basawakulama, Habaranawewa, Medawachchiyawewa, Nuwarawewa, Tisawewa and Kantalewewa have diverse cyanobacteria together with green algae and some diatoms. Among these the dominant cyanobacteria recorded belonged to the genera Oscillatoria, Lyngbya, Tolypothrix, Scytonema, Hapalosiphon, Rivularia and Gleoetrichia. What is noteworthy is the non-dominance of notorious toxin producing genera like Microcystis, Cylindrospermopsis, Anabena and Nodularia which have been reported as occasionally present at that time.

Re-examining the samples collected from Sri Lanka by Professor Fritsch in 1903, Crow (1923) published a checklist on the Taxonomy of the Genus Microcystis in Sri Lanka. While reporting the widespread occurrence of this genus among the cyanobacterial collections of Fritsch, Crow has recorded the dominance of Microcystis only in the Colombo Lake (Beira Lake). Holsinger (1955) has reported on the distribution and periodicity of the phytoplankton in three inland Lakes: one from the lowland dry zone, one in Colombo and the other from the cool, mountain region (possibly Nuwara Eliya). While reporting on the dominance of Myxophyceae (cyanobacteria) in the lowland warm waters (95 \& 87\%), he has recorded a preponderance of diatoms $(67 \%)$ in the lake from the mountainous region. The frequent presence of Arthrospira in the Beira Lake has been recorded in this report. Thus by mid $-20^{\text {th }}$ century inland waters of the warm regions in Sri Lanka were already showing a dominant presence of cyanobacteria.

Periodic observations made and reported from waters of the Beira Lake in Colombo towards the latter part of the $20^{\text {th }}$ century provide strong evidence of the effect of pollution on its phytoplankton population. Costa and De Silva (1978) has reported the presence of 33 genera belonging to green algae, diatoms and cyanobacteria. According to Hirimburegama (1998) a survey conducted by the National Aquatic Resources Research and Development 
Agency in 1990 showed that this population diversity has reduced to 17 genera having a predominance of cyanobacteria together with the occasional presence of green algae and diatoms. A 2-month survey conducted by the University of Colombo in 1993 reported that the phytoplankton population observed was confined to two genera of cyanobacteria namely Microcystis and Arthrospira, both potentially toxigenic species (Hirimburegama, 1998). What is evident from these reports on the Beira Lake is that when alentic water body receives excessive nutrient inflows (gets eutrophied) phytoplankton organisms sensitive to such pollution gradually disappear and the more resistant species survive and become dominant. Besides other adaptive mechanisms, toxin production by cyanobacteria has been cited as a defense mechanism for such survival (Carmichael, 1992)

A survey has been carried out during 1997 - 1998 on the phytoplankton populations of 12 inland reservoirs which are used for water supply schemes by the NWSDB (Jayawardana et al., 1998).In 10 of them all located in the North Central Province of the low country dry zone, the dominant and the sub-dominant cyanobacterial species were toxin producing Microcystis and Cylindrospermopsis. Only the two reservoirs at Labugama and Kalatuwawa located in the low country wet zone and used for water supply schemes to Colombo did not show the presence of cyanobacteria.It is noteworthy that the catchment areas of both these reservoirs are protected rainforests.

A comparative study on the phytoplankton populations of Tisawewa and Basawakulama reservoirs of Anuradhapura was conducted in 1995-96 (Weerakoon et al., 1998). While the total cyanobacterial density was significantly higher at Tisawewa with Cylindrospermopsis being dominant, the density at Basawakulama was much lower and Cylindrospermopsis was only occasionally observed. In Basawakulama the 'filamentous diatom' Aulacosiera (synMelosira) was the commonest. This difference was surprising because these two reservoirs are situated adjacent to one another and during periods of high inflows water overflows from Tisawewa to Basawakulama. An obvious difference between these two reservoirs is the high density and diversity of aquatic macrophytes in Basawakulama compared to those of Tisawewa. It was hypothesized that this aquatic vegetation provides a more favorable ecological niche to zooplankton and other algal grazers which could have a regulatory effect on the phytoplankton. Silva (1998) also reported the occurrence of an Anabaena sp. with a relative abundance of $70 \%$ in the Ambewela reservoir which is the $1^{\text {st }}$ reservoir in the Mahaweli catchment area while in the Kande-Ela reservoir immediately downstream this cyanobacterium showed only a $1 \%$ relative abundance.

Based upon investigations conducted from 1986 to 1991 Piyasiri (1995) reported on eutrophication and the algae problem in the Kothmale reservoir. In 1991, this reservoir was covered with a thick bloom of Microcystisaeruginosa which was more than one meter thick near the dam (S. A. Kulasooriya, personal observation). According to the study of Piyasiri (1995) the Kothmale tributary which is the main source of water to the reservoir which passes through highly fertilized tea estates brings in loads of nutrients that remain entrapped in the bottom hypolimnetic regions of the reservoir. During drought periods the water level of the reservoir drops in the upstream regions facilitating mixing and release of sediment trapped nutrients resulting in eutrophication. This nutrient loading particularly phosphorus and nitrogen initiates bloom formation by the dominant species M.aeruginosa which gets drifted towards the dam due to wind movement and increases its thickness. The bloom eventually extends to cover the entire surface area of the reservoir. Once the wet season rainfall returns the water spills over along the cascade of Mahaweli reservoirs and the algal bloom disappears due to the dilution of nutrients.

In a limnological study of Kothmale, Victoria and Randenigala, the three large manmade reservoirs under the Mahaweli Hydro Power Development Scheme, de Silva (1996) recorded the presence of 15 species of cyanobacteria belonging to 14 genera. Microcystissp was dominant and present throughout the year during the 3 year survey period together with Merismopedia (Syn. Agmenellum). Anabaena and Oscillatoria were occasionally observed in all three reservoirs, but Cylindrospermopsis was not observed.

In a report on the occurrence of cyanobacteria in the Mahaweli reservoirs of Sri Lanka, Silva and Wijeyaratne (1999) recorded 40 
species belonging to 25 genera. Among them, only Microcystishas been recorded as widely distributed. It was found in 20 out of the 21 reservoirs surveyed with a relative abundance ranging from 2 to $46 \%$ showing the highest distribution of 4742 with a dominant index of 0.227 . On the other hand Planktolyngbya had the lowest distribution of 0.048 with a dominant index of 0.0004. This report also records the presence of Pseudoanabaena in 4 reservoirs with relative abundances ranging from 4 to $46 \%$. It reported the occasional presence of Anabaena aphanizomenoides as floating scums in the Parakrama Samudra. A bloom of Anabaena aphanizomenoides has been reported in this reservoir in 2001 in an internal memorandum to the NWSDB by J. P. Padmasiri, Chief Chemist of the Central Region. This shows that given the right conditions bloom formation can happen even by occasionally present cyanobacterial species.

All these reports provide evidences of a significant increase of cyanobacteria in freshwater bodies of Sri Lanka towards the end of the $20^{\text {th }}$ century. It is also noteworthy that the toxigenic Cylindrospermopsisraciborskii which has hardly been observed earlier was getting more frequently observed. By the turn of the century most of the research articles on the freshwater phytoplankton of Sri Lanka report on the widespread occurrence of cyanobacteria with a predominance of toxigenic species, notably Cylindrospermopsis raciborskii, Microcystis aeruginosa and Anabaena sp. It is most likely that the increase and spread of human habitation together with enhanced anthropogenic activities leading to pollution of water bodies resulted in the increase of total cyanobacterial populations and the dominance of toxigenic species that could tolerate pollution better than the other phytoplankton.

\section{THE $21^{\text {ST }}$ CENTURY SCENARIO}

Awareness of the dominant presence of toxigenic cyanobacteria in most of the sources used for water supply schemes had a beneficial impact. The NWSDB (influenced by overseas aid agencies that provide funding for water supply schemes) introduced a condition to obtain survey reports on algae (including cyanobacteria) in water sources to be used for such projects as a pre-requisite for their commissioning. The NWSDB (Central Regional Office, Kandy) sought the services of the author to examine and report on water sources earmarked for water supply schemes. Unpublished data recorded during these examinations are hereby presented as personal observations of S. A. Kulasooriya and Jilushi Dhamunupola.

The first survey under these schemes commenced in 2004 for Unnichchai Tank to be used as a source for a water supply scheme for Batticaloa in the Eastern Province. Water samples from this tank have been taken from locations where human activities such as bathing and fishing with small catamarans were taking place, close to the left and right bank sluice gates and from deeper waters away from human settlements. Almost 4/5th of the tank periphery is surrounded by dry zone scrub jungle but a herd of around 15,000 heads of domestic cattle are let loose to graze in these areas. Such background information shows that this source of water is not entirely free from anthropogenic influence but the inflow and a good part of the catchments are scrub jungle with sporadic chena cultivations.

Water samples were collected by field officers of the project under our guidance. Samples were collected from 9 to 14 locations during the months of July, August, September, October and November, 2004. From each location a surface and a $0.5 \mathrm{~m}$ depth sub-surface sample was taken. These were collected in $0.5 \mathrm{~L}$ narrow mouthed clean plastic mineral water bottles and Lugol's iodine was added immediately after collection. These samples were packed in Rigiform boxes, cooled by placing ice blocks among them, transported to the project office and kept under refrigeration until they were handed over to us. These samples concentrated from $0.5 \mathrm{~L}$ to $60 \mathrm{ml}$ by centrifugation were observed under the microscope for qualitative and quantitative analyses without further concentration. Triplicate $1 \mathrm{ml}$ sub-samples from each concentrated sample were counted using a Sedgewick Rafter counting cell.

Sixteen different genera of phytoplankton belonging to Chlorophyta (07), Cyanophyta (05) and Bacillariophyta (04) were observed. Among them only three genera of Cyanophyta were present in significant numbers and all the others were occasional $(<20 / \mathrm{ml})$ or rare $(<10 / \mathrm{ml})$. 
Table 1: Dominant and sub-dominant cyanobacterial counts ( $\mathrm{cfu} / \mathrm{ml} *)$ of Unnichai tank. Numbers in parentheses are their \% relative abundance.

\begin{tabular}{llllll}
\hline $\begin{array}{l}\text { Cyanobacterial } \\
\text { Species }\end{array}$ & Jul & Aug & Sept & Oct & Nov \\
\hline Cylindrospermopsis & 372 & 1050 & 1780 & 1814 & 1052 \\
& $(30)$ & $(34)$ & $(54)$ & $(66)$ & $(64)$ \\
\hline Microcystis & 98 & 1785 & 1490 & 649 & 402 \\
& $(8)$ & $(58)$ & $(45)$ & $(24)$ & $(25)$ \\
\hline Spirulina & 150 & 653 & 530 & 256 & 138 \\
& $(12)$ & $(21)$ & $(16)$ & $(9)$ & $(8)$ \\
\hline Total & 1240 & 3488 & 3800 & 2719 & 1592 \\
\hline
\end{tabular}

*Colony forming units which include single cells, colony fragments and pieces of filaments

Table 1 show that the total numbers of phytoplankton organisms are not high, the dominant genera are cyanobacteria and two of them, namely Cylindrospermopsis and Microcystis are toxigenic. The non-significant variations among the dominant cyanobacteria during the five month monitoring period could be due to dilution effects by rain. Judging by the relatively low density of the total phytoplankton population, pollution of this tank appears to be low as the periphery of the tank is largely lined by scrub jungle. However, human activities close to the left and right bank sluice gates if left unmitigated could increase pollution and bloom formation by one or more of the dominant toxigenic cyanobacteria is a possibility.

Qualitative and quantitative estimations of the phytoplankton populations in Madawalasingham, Sagamam and Pannelagama tanks earmarked as sources of water for Mulativu and Thirukkovil water supply schemes were done in 2005. These estimations were done on representative samples collected, fixed in Lugol's iodine and supplied to us by contractors for the NWSDB. Five to nine $2 \mathrm{~L}$ water samples were provided from the respective tanks collected from the inlet, middle and outlet points. These samples have been collected in October and November, 2005 and February 2006 between 10.00 a.m. and 2.00 p.m. from the surface and sub-surface $(0.5 \mathrm{~m}$ depth). Each replicated sample was examined separately.

Each sample was swirled and thoroughly mixed, triplicate $10 \mathrm{ml}$ representative subsamples were centrifuged to concentrate. Each concentrated pellet was re-suspended in $2 \mathrm{ml}$ of water and $1 \mathrm{ml}$ aliquots observed on a Sedgewick Rafter counting cell for qualitative and quantitative estimations. Analyses of samples from the Sagamam tank collected in October 2005 and November 2005 respectively, had a phytoplankton population with some diversity and a dominance of cyanobacteria associated with certain green algae and diatoms. There was little variation in the total population of organisms being around 31,000 and 32,000 colony forming units (cfu) per milliliter in October and November. This was a high population and the diversity remained the same. The dominant species was Cylindrospermopsisraciborskii in both samples with relative abundance (RA) values of 90 and $89 \%$ followed by Spirulina sp. having RA values of 3.4 and $7.4 \%$. Among the diatoms Aulocasiera (syn. Melosira) gave RA values of 2.8 and $0.06 \%$ and the green alga Pediastrum (a desmid) was observed only occasionally.

On the other hand water samples from Pannalagama tank showed very low numbers of total phytoplankton $(<100$ organisms $/ \mathrm{ml})$, with a negligible presence of cyanobacteria. Examination of the Sri Lanka 1:50,000 map of Thirukkovil \& Tampaddai areas show that the the Sagamam tank is surrounded by paddy fields and human habitations whereas Pannalagama tank is surrounded by forest and scrub jungle.

Similarly low population densities with equal diversity of different algal species were observed with water samples of the Madawalasingham reservoir which is also surrounded largely by uninhabited scrub jungle.

Yet another survey was carried out in 2006 on the waters of a cascade of irrigation tanks starting from the Senanayake Samudra, passing through Himidurawa and Aligalge tanks 
terminating in the Konduwattuwana tank earmarked for a water supply scheme for Amparai. This survey revealed that water from the Senanayake Samudra which is virtually surrounded by the Lahugala forest reserve, had very little phytoplankton. Microscopic observations of eight representative samples collected from this reservoir showed a very low total population of 23 organisms per $\mathrm{ml}$ of total phytoplankton. Its diversity was represented by 6 Chlorophyta, one diatom sp. and two genera of cyanobacteria. This population underwent an increase in its total density with the dominant species of Cylindrospermopsis raciborskii undergoing a progressive increase as the water passed through Himidurawa and Aligalge tanks surrounded by paddy fields and human settlements. This phytoplankton reached an extremely high diversity and population density (Fig.1) with the toxigenic $C$. rasiborskii giving a count of 14,000 colony forming units per $\mathrm{ml}$ as the water accumulated in the terminal Konduwattuwana tank (personal observations of S. A. Kulasooriya, E. I. L. Silva and Namal Priyantha). Such observations have been confirmed by Silva et al. (2013) who reported C.raciborskii attaining maximum growth during the dry seasons in eutrophic-hypereutrophic terminal irrigation reservoirs that experience long water retention times and receiving urban waste.

The foregoing unpublished data demonstrate that lentic water bodies surrounded by forests with little or no human activities remain relatively clean having low densities of phytoplankton with few cyanobacteria. They lend support to the observations of Jayawardene et al. (1998) and Jayatissa et al. (2006) who reported very low phytoplankton densities and negligible presence of cyanobacteria in the waters of Labugama and Kalatuwawa reservoirs whose catchments are protected forests. When such water passes through areas of human habitation it collects pollutants mostly from human activities and the phytoplankton populations undergo dramatic increases usually with a dominant presence of toxigenic cyanobacteria.

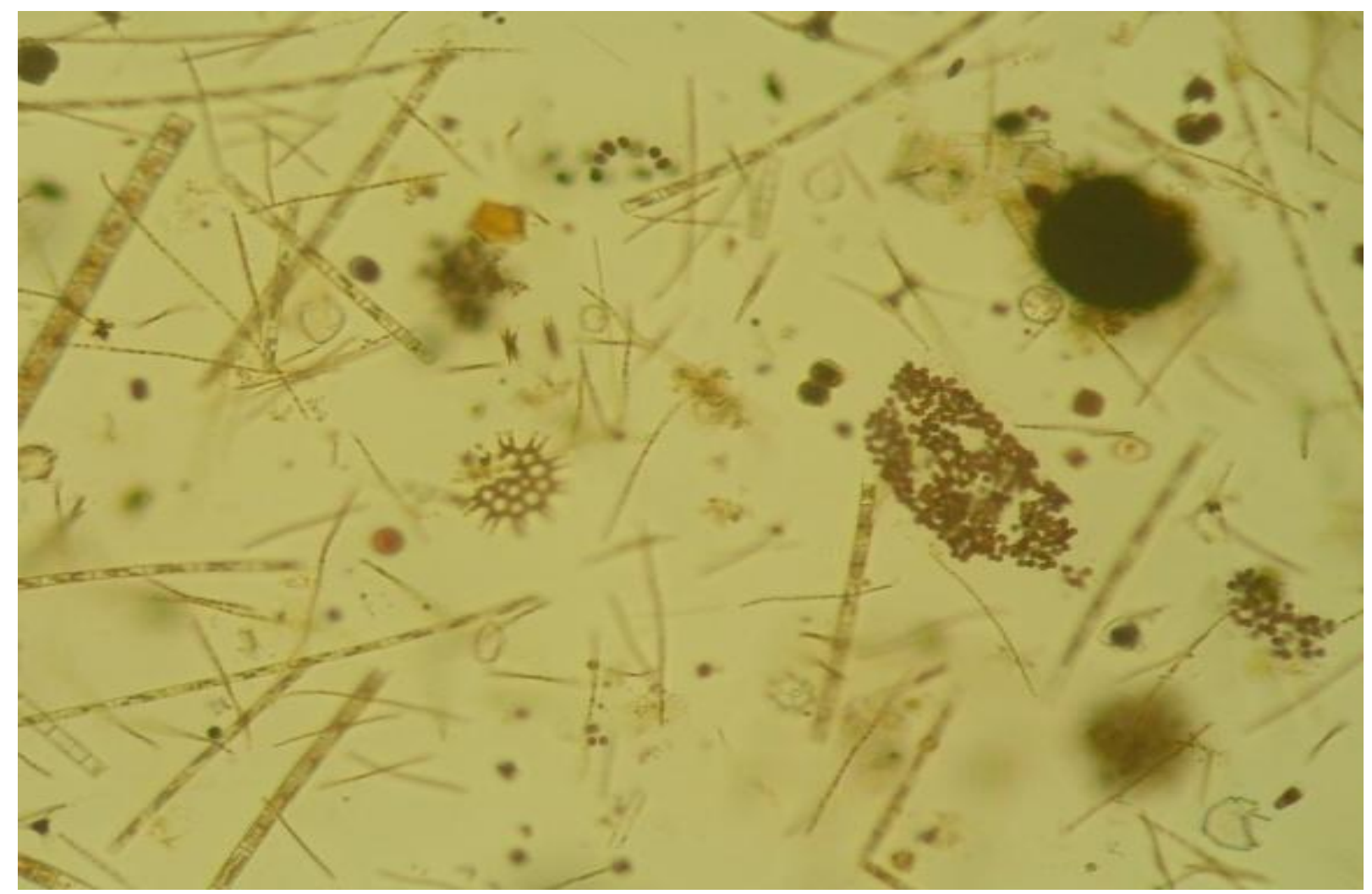

Figure 1: Phytoplankton diversity of Konduwattuwana Tank: Note numerous small filaments of Cylindrospermopsis, few colonies of Microcystis, several desmids and the diatom Acaulosiera. 
Jayatissa et al. (2006) reported on a comprehensive study on the phytoplankton of 17 freshwater bodies with special emphasis on the presence of cyanobacteria and their relationship to the nitrogen and phosphorus levels of these waters. They found that the biomass of total phytoplankton, the dominance of cyanobacteria, the concentration of $\mathrm{N}$ and $\mathrm{P}$ was lowest in drinking water reservoirs, $2^{\text {nd }}$ in hydro-power reservoirs and highest in irrigation reservoirs. However, the dominance of Microcystis sp. was high in hydro-power reservoirs.It is also important to note that Cylindrospermopsis did not show either a dominant presence or gained a high rank in their Important Value Index (IVI) in any of the dry zone irrigation tanks surveyed by them. All the irrigation tankssurveyed in this study are from the Southern low country dry zone. On the other hand Cylindrospermopsis has been reported to be dominant in most of the irrigation tanks located in the dry zone areas of the North Central Province (Jayawardene et al., 1998; Silva, 2013; Silva et al., 2013 and Perera et al., 2013). These results perhaps indicate certain geographic differences in the distribution of toxin producing cyanobacterial species in Sri Lanka, but this need further studies for confirmation.

A series of International Symposia entitled Water Quality and Human Health: Challenges Ahead, have beenheld in the years 2012, 2013, 2014, 2015 and 2016 at the Postgraduate Institute of Science, University of Peradeniya, Sri Lanka. Several presentations on freshwater phytoplankton and cyanobacteriain Sri Lanka are found in their proceedings but only the abstracts have been published.

Perera et al. (2012) have reported on the prevalence of toxigenic cyanobacteria in different climatic zones of Sri Lanka. This study covered 20 freshwater reservoirs located in the lowland dry and arid zones, the intermediate zone and the lowland and upland wet zones. Higher diverse populations of cyanobacteria were recorded from the dry zone reservoirs whilelower densities were recorded from those of the intermediate zone.The highest record of toxigenic species was found in the Ridiyagama tank located in the Southern arid zonewhile the lowest was in the Kandy Lake in the mid-country wet zone. All the reservoirs in the dry zone of the North Central Provinceshowed the presence of toxigenic species with Cylindrospermopsis raciborskii being frequently dominant. This species was also recordedfor the first timein the highland Lake Gregory of Nuwara Eliya. This clearly showed that toxigenic species have spread to the cooler highlands towards the turn of the century.According to this report the dominant toxigenic species were Cylindrospermopsis raciborskii and Microcystis aeruginosa together with the occasional presence of Anabaena, Nodularia and Lyngbya. Among the limnological factors that favored cyanobacterial growth, high temperature, high light, low water levels and high levels of available $\mathrm{P}$ and $\mathrm{N}$ were reported.

In a presentation followed by a research publication (Silva, 2013; Silva et al., 2013) have reported on species composition and relative dominance of reservoir phytoplankton in Sri Lanka.In these reports inland water bodies of Sri Lanka have been categorized into three distinct groups as oligo-mesotrophic (large, deep newly built hydro-power reservoirs), meso-eutrophic (dry zone irrigation tanks subjected to high flushing rates) and eutrophic-hypereutrophic (terminal irrigation reservoirs experiencing long retention times and receiving urban waste). Thiscomprehensive publication has incorporated data and provided detailed information on the work done on 57 manmade water bodies for several years. In the qualitative analysis of the phytoplankton it is reported that desmids presented the highest number of taxa and some species were numerically dominant in the oligomesotrophic waters. Species richness between the Chlorophyta (green algae) and Cyanobacteria (blue-green algae) was similar. Among the cyanobacteria many toxigenic species have been recorded but only Microcystis aeruginosa and Cylindrospermopsis raciborskii formed periodic blooms in certain reservoirs, some of which are used as sources for drinking water supply schemes. Among the Bacillariophyta (diatoms) Aulacosiera granulata was dominant both in numbers and bio-volume and oscillated with the desmid Pediastrum simplex in meso-eutrophic water subjected to periodic rhythmic water level fluctuations. In both these papers they conclude that Cylindrospermopsis raciborskii attains maximum growth under low water levels during the dry seasons in most irrigation reservoirs, particularly the eutrophic-hypereutrophicterminal irrigation reservoirs experiencing long retention times and receiving urban waste.Such water bodies having a dominant presence of toxigenic 
cyanobacteria pose a grave health risk to the user population.

Most of the conclusions of Silva et al. (2013) on the occurrence and distribution of $C$. raciborskii were supported by a presentation made by Perera et al.,(2013). This report was based upon a survey carried out from 2010 to 2012 on 60 reservoirs of varying sizes representing all the climatic regions of Sri Lanka from which water sampling was done at bimonthly intervals. According to this report C.raciborskii is dominant in shallow urban reservoirs during the dry season, terminal reservoirs with low flushing rates and in deep reservoirs with persistent water stratification especially during the dry seasons. This species also exhibited several morpho types. Though characteristically it has slightly coiled filaments with terminal triangular heterocysts, their filaments exhibit straight, sigmoid and trichomatous shapes particularly in highly eutrophic water bodies. It was also observed that the cell size of this cyanobacterium found in a high altitudinal wet zone reservoir which had a temperature fluctuation ranging between 10 $20^{\circ} \mathrm{C}$ throughout the year, was exceptionally large.

Hettiarachchi et al. (2013) also presented results of a survey on nuisance algae and cyanobacteria conducted on 15 water bodies that were used for drinking and irrigation purposes. Representative water samples collected from February 2010 to December 2011were analyzed for species composition and abundance of phytoplankton. Among the cyanobacteria detected Microcystis aeruginosa, Cylindrospermopsi sraciborskii and Anabaena $s p$. were dominant in all the reservoirs which recorded high levels of total $\mathrm{P}$. While in situ detection of microcystins was done by immunostrips, confirmation and quantification of the toxins were done by HPLC under laboratory conditions. Only water from the Kattakaduwa tank contained $10 \mu \mathrm{g} / \mathrm{L}$ of microcystin-LR which was well above the safe limit of $1.0 \mu \mathrm{g} / \mathrm{L}$ given by the WHO for drinking water. This water also had the highest level of total phosphate (3.73 $\mathrm{mg} / \mathrm{l}$ ) among all the water bodies surveyed.

In another presentation Perera and Yatigammana (2014) reported on the distribution and composition of cyanobacteria in 62 reservoirs of different morphometric characteristics located in dry zone, arid zone, intermediate zone, wet zone and the highland wet zone of Sri Lanka. All the reservoirs were found to be eutrophic with total P-levels higher than $30 \mu \mathrm{g} / \mathrm{L}$, salinity greater than 1 part per trillion and specific conductance ranging from $38 \mu \mathrm{s} / \mathrm{cm}$ to $637 \mu \mathrm{s} / \mathrm{cm}$.Examining plankton net collectedwatersamples at three monthly intervals, they found Merismopedia (Agmenellum) punctata to be most widely distributed being recorded in all the reservoirs examined while Anabaena circinalis was recorded only in three reservoirs all located in the highland wet zone where the temperatures were comparable to global temperate zones.The toxigenic cyanobacteria were dominated by Microcystis aeruginosa, Cylindrospermopsis racibirskii together with Oscillatoia sp., Anabaena sp., Aphanizomenon sp., Anabaenopsis sp. And Nostocsp which were widely distributed and abundant in urban reservoirs.

\section{CYANOBACTERIAL TOXINS}

The nature and toxicology of cyanobacterial toxins has been presented initially in Sri Lanka by Dr. Glen Shaw of the National Research Center for Environmental Toxicology, Queensland, Australia (Shaw, 1998). In this presentation he has given a broad general account of the major types of cyanotoxins including their chemical structures, their toxicology as hepatotoxins, neurotoxins, ion channel blockersand tumor promoters etc., methods for their detection in the environment, their degradation and the factors contributing to their production.

Jayatissa et al. (2006) reported the first analyses for microcystin-LR carried out on freshwater cyanobacteria collected from Sri Lanka. These have been done on extracts from freeze dried cyanobacterial material prepared by filtering reservoir water through $110 \mathrm{~mm}$ Whatman GF/C filter paper. More than half the bloom material (Microcystis) analyzed contained up to $81 \mu \mathrm{g} / \mathrm{l}$ of the toxin microcystin LR.

A presentation made by Liyanage and Magana-Arachchi (2012) on cyanobacterial toxins, has been followed by a complete research publication by Magana-Arachchi and Liyanage (2012). These reports demonstrated the presence of cylindrospermopsin $(\mathrm{CYN})$ the toxin produced by Cylindrospermopsis using molecular, 
biochemical and bioassay methods. Analysis have been carried out on water samples collected from Kalawewa, Nuwarawewa, Tisawewa and Jayaganga of the Anuradhapura District from where a high prevalence of Chronic Kidney Disease of Uncertain etiology (CKDu) has been reported. In these samples the dominant toxigenic cyanobacterium was Cylindrospermopsis along with Microcystis, Anabaena, Chroococcus, Phormidium and Oscillatoria present as occasional species. Using an ELISA detection kit they have confirmed and quantified the presence of CYN in these waters. All the water samples were positive for the presence of the toxin with an average concentration of $0.137 \mathrm{ng} / \mathrm{ml}$. Bioassay results reported by them also confirmed the presence of CYN in all the samples tested. They demonstrated that the concentration of $0.245 \mathrm{ng} / \mathrm{ml}$ was reduced to $0.154 \mathrm{ng} / \mathrm{ml}$ of CYN after addition of chlorine to samples collected at the Anuradhapura water purification plant. A sample that has undergone the complete treatment at this plant was negative for CYN showing that the treatment has been effective in eliminating the toxin. These determinations were confirmed and quantified by the application of High Performance Liquid Chromatography (HPLC) using CYN standards (Liyangae et al., 2014)

Subsequently Liyanage et al. (2016c) published detail results of toxins identified from cyanobacteria isolated and cultured in the laboratory as well as from unculturable taxa using molecular techniques primarily based upon the 16srRNA genes. This study has been done on water samples collected from Tisawewa, Nuwarawewa, Kalawewa, Jayaganga and Nacchchaduwawewa in the Anuradhapura district, Ulhitiyaand MinipeEla reservoirs in Girandurukotte in the Polonnaruwa district and Nikawewa in the Kurunegala district, all major CKDu prevalent areas in the dry zone.

A brief review on the toxicology of cynaobacteria has been presented by MaganaArachci (2016) and this has been followed by a more comprehensive research paper by Liaynage et al. (2016b) in which detailed information on these toxins including results of studies conducted in Sri Lanka have been reported.

Shihana et al. (2012) demonstrated the induction of acute tubular necrosis (ATN) in the kidneys of experimental mice fed with diluted water extracts of Microcystis, Cylindrospermopsis and Lyngbya collected from the Padaviya reservoir. All the animals fed with such extracts developed ATN within a week. Another set of animals fed with toxin containing cyanobacterial extracts followed by two weeks of feeding with normal water was shown to be capable of reversing this condition to some extent. These results confirm those demonstrated overseas for nephrotoxic effects by cyanobacterial toxins on experimental animals (Bhattacharya et al., 1997 and Rymuszka and Sieroslawaska, 2009). An attempt by Dissanayake et al. (2012) to demonstrate the effect of feeding water from the Padaviya reservoir (in which toxigenic cyanobacteria were predominant) to experimental mice in comparison to feeding normal water from Kandy did not give conclusive results. The amount of cyanobacterial toxins in the concentrated water from Padaviya was detected to be very low $(0.05 \mu \mathrm{g} / \mathrm{l})$. The raw water from the reservoir was concentrated by solar evaporation. During such exposure most of the cyanobacterial toxins could have been broken down by the ultra violet rays of the sun to which these toxins are susceptible.

\section{AMELIORATION OF CYANOBACTERIAL PROBLEMS}

From the foregoing it is evident that toxigenic cyanobacteria are widespread in lentic freshwater bodies of Sri Lanka and frequently form blooms when conditions favorable for their proliferation occur. High temperature, high light, long water retention times, low water levels leading to increased concentrations of available nutrients (especially $\mathrm{P}$ and $\mathrm{N}$ ) are the major factors that promote the preponderance of toxigenic cyanobacteria and their bloom formation. Nutrient loading leading to eutrophication of such water bodies is related to human habitation and anthropogenic activities. These activities could either be direct such as washing, bathing, application of fertilizer and other agro-chemicals to adjoining cultivations or indirect by similar activities taking place in other locations being washed down along rivers, streams and canals finally ending up in the lentic water reservoirs and irrigation tanks. This is corroborated by surveys cited in this paper in which very low numbers of phytoplankton including few cyanobacteria were observed when water bodies are either having catchment areas of protected 
forests (Jayawardene et al., 1998) or surrounded by scrub jungle largely uninhabited by humans (Kulasooriya, Dhamunupola, Silva and Namal Priyantha unpublished data).Expansion of protected forest cover in water catchment areas, restricting human habitation of catchment areas and minimizing Chenas (shifting cultivations) in scrub jungles close to inland reservoirs could therefore be adopted as methods of mitigation.

While it would be impracticable to discourage people using reservoir waters in populated areas for crop production and other domestic purposes, certain steps can be taken to minimize water pollution. In this respect the policy decision of the Government to reduce the application of chemical fertilizer and other agrochemicals in crop production is appropriate and timely. It should however be implemented with due caution and alternativesshould be provided in order to avoid a drop in crop yields that would negatively impact farmer incomes and national food security. Invariably there should be a period of transition during which a judicious combination of synthetic chemical and nonsynthetic natural fertilizers is used. Organic matter such as green manure, animal dung and compost fertilizers are the more common natural substitutes generally recommended. However, these are bulky and large quantities have to be added to effectively replace concentrated chemical fertilizers. The slow availability of nutrients from organic fertilizers is also a limitation for high yielding, short-term, annual crops such as rice, maize, many pulse legumes and several vegetables. On the other hand biofertilizers (living microbial inoculants that provide nutrients to crops while they continue to live) can be used for successful crop production without compromising on yields. For example, rhizobial inoculants produced in Sri Lanka have been shown to completely replace the use of urea in soybean, mung bean and vegetable bean cultivations sometimes even with a marginal increase in crop yields (Kulasooriya et al., 2014). Similarly the introduction of the novel biofilmbiofertilizers (multi-microbial inoculants in biofilm mode), have been shown to be capable of replacing at least $50 \%$ of all three major chemical fertilizers (N,P \& K) applied to several non-leguminous crops such as rice, maize, vegetables and plantation crops like tea, rubber and coconut (Buddhika et al., 2016). Further research and development of novel biofertilizers for the rapid decomposition of organic matter and popularization of their use together with the return to the use of organic fertilizers (as much as possible) is a way forward to minimize water pollution in large scale agriculture in Sri Lanka. In this manner restoration of beneficial microbial communities in soil (Seneviratne and Kulasooriya, 2013) resulting in the retention of added fertilizer and improvement of natural soil fertility could lead to sustainable, environmentally benign crop production.

It should be realized that nutrients in water are largely transported as particle bound colloidal matter. Such movements can be effectively reduced and retained by establishing riparian vegetation utilizing aquatic tolerant trees like Terminalia arjuna ('Kumbuk') together with the introduction of associated reeds and other rooted aquatic plants. Such vegetation will not only consolidate the river banks, but also slow down water flows and trap and retain most of particle bound nutrients in them. The absorption of nutrients from the retained debris will minimize their eventual flow into the stagnant water bodies.These riparian vegetationwill also provide micro-niches for the survival and proliferation of zooplankton communities such as daphnids, copepods and crustaceans that would consume algal and cyanobacterial propagules and minimize them reaching the water bodies. Restoration of riparian vegetation has been shown to reduce the surface and groundwater contamination in Kalmunai and Kalpitiya areas in the aftermath of the Tsunami in Sri Lanka (Melvani and Moles, 2013). Such foresight and indigenous technology has been historically recorded as been practiced by our kings who established an exemplary system of ancient agrarian civilization which made Sri Lanka the granary of Asia (Kulasooriya, 2014). It is time to re-visit those traditional practices, conduct research based upon such knowledge and develop technologies applicable to modern day large scale crop production systems.

\section{BREAKDOWN OF CYANOBACTERIAL TOXINS THROUGH WATER TREATMENT}

In his general presentation on cyanobacterial toxins Shaw (1998) briefly covered the methods used for the degradation of such toxins. While neurotoxins like anatoxin-a are relatively labile and can degrade even under natural conditions like high $\mathrm{pH}$, cyclic peptide toxins such as 
microcystin-LR can be quite stable and even withstand boiling. Cylindrospermopsin is also stable but undergoes degradation when exposed to direct sunlight.

It has already been observed that conventional water purification methods practiced by the NWSDB at Anuradhapura could reduce the cyanotoxincylindrospermopsin to levels declared safe by the WHO (MaganaArachchi and Liyanage, 2012). However the same cannot be said of microcystin LR which appear to be able to withstand standard water treatment procedures. On the other hand Moringa oleifera (Murunga) seeds have been used traditionally as a domestic flocculent to clear turbid water. A preliminary investigation was carried out see the effect of intact as well as crushed Moringa seeds in clearing and breaking down of microcystins in water from the Beira Lake and from a Microcystis aeruginosa culture (Wanigatunga et al., 2015). Turbidity of the water samples was measured by a turbidity meter, cell counts were determined by a Sedgewick-Rafter cell counter and the toxin microcystin was estimated by Micro Cystest kit. Extracts of both dried and fresh ripened seeds were effective coagulants and produced clear water. However microcystin breakdown could be recorded only with the extracts of the ripe fresh seeds after exposure for 24 hours. These preliminary results are only indicative and needs to be confirmed and reproduced.

Having briefly reviewed biomanipulation techniques generally applied in foreign countries Yatigammana et al. (2013) have proposed the commencement of research studies on biomanipulation for the control of algal bloom formation in our reservoirs. They have suggested testing the introduction of native Snakehead Channastriata and large herbivorous zooplankton for this purpose.

Silva and Manage (2015) has tested the possibility of using naturally occurring rutile sand to remove microcystin-LR from drinking water. In vitro laboratory exposure of microcystin extracts to Ultra Violet radiation in the presence of rutile sand, granular $\mathrm{TiO}_{2}$ and powdered $\mathrm{TiO}_{2}$ gave breakdown values of $50 \%$, $63 \%$ and $78 \%$ respectively while UV light by itself produced a $22 \%$ reduction. A filter model using rutile sand showed a $24 \%, 38 \%, 49 \%$ and $53 \%$ removal of Microcystin-LR after 60, 120,
180 and 240 minutes exposure at a water circulation rate of $500 \mathrm{~L} / \mathrm{h}$.

In a laboratory incubation study under sterile conditions Dharmadasa et al., (2015) have demonstrated the potential of three native bacteria to degrade microcystin-LR extracted from water samples of Beira Lake. All three bacteria Enterobacter sp., Enterobacterludwigii and Bacillus cereus showed their ability to break down microcystin-LR. Although it was suggested to use these organisms as agents of bioremediation, there is a long way to go prior to such applications are developed under non-sterile natural environmental conditions in the presence of a myriad of other microbial populations. Idroos et al. (2015) have reported on an attempt to optimize the conditions for the degradation of microcystin-LR by isolated native bacteria such as Bacillus cereus, Rahnella aquatilis and Stentrophomonas maltophila. In this preliminary study all three bacterial strains examined showed highest rates of degradation at $32^{\circ} \mathrm{C}$ while at $18^{\circ} \mathrm{C}$ degradation it was inhibited. Rates of degradation increased from phosphate concentrations of 0.005 to $0.01 \mathrm{mg} / \mathrm{L}$ while beyond this concentration there was a decline. Nitrate concentrations of up to $0.4 \mathrm{mg} / \mathrm{L}$ and $0.5 \mathrm{mg} / \mathrm{L}$ increased the rates of microcystin-LR degradation. It was suggested that biofilms formed by these strains could be utilized under such optimized conditions to remove microcystin-LR from water, but further research and development are needed prior to application of such methods.

\section{CONCLUSION}

From the foregoing it is evident that toxigenic cyanobacteria as well as their toxins are present in most of the freshwater resources of Sri Lanka. They not only contribute to environmental health problems, but if left unmitigated could develop into a major environmental health hazard. All efforts should therefore be made to support and promote multi-disciplinary research studies aimed at the overall reduction of water pollution, minimizing the proliferation and bloom formation of toxigenic cyanobacteria in water bodies of Sri Lanka and for the development of novel technologies for the breakdown of cyanobacterial toxins. 


\section{REFERENCES}

Battacharya, A., R., Sugendran, K., Dangi, R. S. and Rao, P. V. (1997) Toxicity evaluation of freshwater cyanobacterium Microcystisaeruginosa PCC 7806: II. Nephrotoxicity in rats Biomedical Environmental Science, 10 (1): 93-101.

Buddhika, U. V. A., Seneviratne G., Ekanayake E. M. H. G. S.., Dsanayake, M. N., Igalavithane, A. D., Weeraratne, N., Jayasekara, A. P. D. A., Weerakoon, W. L., Indrajith, A., Gunaratne, H. M. A. C., Kumara R. K. G. K., De Silva M. S. D. L. and Kennedy, I. R. (2016). Biofilmed Biofertilizers: Application in Agroecosystems. Chapter 6, In: The Handbook of Microbial Resources, (eds. V. K. Gupta et al), CAB International, London: 96-106.

Carmichael, W. W. (1992).Cyanobacterial secondary metabolites - the cyanotoxins. Journal of Applied Bacteriology, 72: 445 - 459.

Codd, G. A. and Poon, G. K. (1988) Cyanobacterial Toxins. In: Rogers, L. J. \& Gallon, J. R. (eds.) Biochemistry of the Algae and Cyanobacteria, Clarendon Press, Oxfod, UK: 283-296.

Costa, H. H. \& De Silva, S. S. (1978). The Hydrobiology of Colombo (Beira) Lake III Seasonal fluctuations of phytoplankton. Spolia Zeylanica, 32, 35-53.

Crow, W. B. (1923). The taxonomy and variation of the genus Microcystis in Ceylon. New Phytologist, 22 (2): 59-68.

de Silva, P.K. (1996). Limnological aspects of three man-made lakes of Sri Lanka. Fresh water Forum, 6: 39 - 56.

Dharmadasa, P. S., Manage, P. M. and Kannangara, S. (2015) Degradation of microcystin-LR by native bacteria. In: Illeperuma, O. A. et al. (eds) Symposium Proceedings, International Symposium on Water Quality and Human Health: Challenges Ahead, 01 \& 02, August, PGIS, Peradeniya, Sri Lanka: p34.

Dharmawardana, C. (2013).Ionocity - a new interpretation for Chronic Kidney Disease of unknown etiology (CKDu). Water Lanka, 1 (4), Oct-Dec, 2013, Water Resources Science and Technology, URL:www.wrst.info.

Dissanayake, D. M. (2015). Cyanobacteria and CKDU: What do we know? Keynote Address, $4^{\text {th }}$ Annual Conference and Scientific Sessions, Sri Lankan Society for Microbiology, 3: xi - xii, October 2015, Oak Ray Regency, Kandy, Sri Lanka.

Dissanayake, D. M., Jayasekera, J. M. K. B., Ratnayake, P., Wickremasinghe, W. Radella, Y. A. \& Palugaswewa, W. B. (2012).Effect of concentrated water from reservoirs of high prevalence area for chronic kidney disease $(\mathrm{CKDu})$ of unknown origin in Sri Lanka on mice. In: Illeperuma, O. A. et al. (eds.) Symposium
Proceedings, International Symposium on Water Quality and Human Health: Challenges Ahead, 22- 23, March PGIS, Peradeniya, Sri Lanka: p.12.

Fristch, F. E. (1907a). A general consideration of the sub-aerial and freshwater algal flora of Ceylon: A contribution to the tropical algal ecology. Part I: Sub-aerial algae and algae of the inland freshwaters. Proceedings of the Royal Society London, B, 79 (531): 197- 254.

Fritsch, F. E. (1907b) The sub-aerial and freshwater algal flora of the tropics: A phytogeographical and ecological study. Annals of Botany, London, 21 (2): 235- 275.

Hettiarachchi, Manage, P., Sumanaweera, S. \& Jayasiriwardene, D. S. D. (2013) Nuisance algae and cyanobacteria in some selected water bodies in Sri Lanka. In: Illeperuma, O. A. et al. (eds) Symposium Proceedings, International Symposium on Water Quality and Human Health: Challenges Ahead, 15 - 16 March, PGIS, Peradeniya, Sri Lanka: p. 33.

Hirimburegama, W. K. (1998) Cyanobacteria in the Beira Lake polluted with urban waste. In: Proceedings of the Symposium on Cyanobacterial Toxins, PGIS, University of Peradeniya, April 1998: 4p.

Holsinger, E.C.T. (1955) The distribution and periodicity of the phytoplankton of three Ceylon lakes. Hydrobiologia, 7: 25. doi:10.1007/ BF00189792.

Idroos, S. F., Manage, P. M., and De Silva, B. G. D. N. K. (2015) Optimization of microcystin-LR degradation rates of isolated freshwater bacterial strains. In: In: Illeperuma, O. A. et al. (eds) Symposium Proceedings, International Symposium on Water Quality and Human Health: Challenges Ahead, 01 \& 02, August, PGIS, Peradeniya, Sri Lanka: p 30.

Jayatilake, Nihal, Mendis, Shanthi, MaheepalaPalitha, Firdosi R. Metha and on behalf of the CKDu National Research Team (2013), Chronic kidney disease of uncertain aetiology: prevalence and causative factors in a developing country. BMC Nephrology 14: 180: 1- 13.

Jayatissa, L. P., Silva, E. I. L., McElhiney, J and Lawton, L. A. (2006) Occurrence of toxigenic cyanobacterial blooms in freshwaters of Sri Lanka. Journal of Systematic and Applied Microbiology, 29 (2): 156 - 164.

Jayawardana, B, P, A., Jayalath, J. M. J. C., Padmasiri, J. P. and Kulasooriya, S. A. (1998) Occurrence of potentially toxin producing cyanobacteria in reservoirs of Sri Lanka. In: Proceedings of the Symposium on Cyanobacterial Toxins, PGIS, University of Peradeniya, April 1998: 7P.

Jeyakumaran, N. (2013) Priorities for cancer prevention in Northern Region of Sri Lanka. In: Voice for Change (ISBN 978-955-4760-00-4) 
Jaffna Manager's Forum 17, Agrarian Services Lane, Nallur, Jaffna: 72- 82.

Kulasooriya, S. A. (2014) Amelioration of pollution of inland freshwater bodies in Sri Lanka. (Keynote lecture), In: Illeperuma, O. A. et al., (eds) Symposium Proceedings, International Symposium on Water Quality and Human Health: Challenges Ahead, 27 - 28, June, PGIS, Peradeniya, Sri Lanka: 3- 6.

Kulasooriya, S. A. (2011) Cyanobacteria: Pioneers of Planet Earth. Ceylon Journal of Science (Bio.Sci.) 40 (2): 71-88.

Kulasooriya, S. A., E. M. H. G. S. Ekanayake, R. K. G. Kosla Kumara \& H. M. A. C. Gunarathna (2014) Use of rhizobial inoculants could minimize environmental health problems in Sri Lanka. Chapter 26, In: Krishna Pramanik \& Jaya Kumar Patra (ed.) Industrial and Environmental Biotechnology, ISBN: 978-93-80012-67-4, Studium Press, New Delhi, India : 433 - 442.

Liyanage, M., Magana-Arachchi, D., Priyadarshika, C., Abeysekera, T. and Guneratne, L. (2016a) Cyanobacteria and Cyanotoxins in well waters of the Girandurukotte, CKDu endemic area in Sri Lanka: Do they drink safe Water? Journal of Ecotechnology Research, 18 (1): 17-21.

Liyanage, H. M., Magana-Arachchi, D. N., Abeysekera, T., and Guneratne, L. (2016b).Toxicology of Freshwater Cyanobacteria. Journal of Environmental Science and Health: Part C, DOI: 10.1080/10590501.2016.1193923.

Liyanage, H. M., Magana-Arachchi, D. N. and Chandrasekaran, N. V. (2016c) Genetic divergence among toxic and non-toxic cyanobacteria of the dry zone of Sri Lanka. Springer Plus (2016) 5:2026 DOI 10.1186/s40064-016-3680-5 .

Liyanage, H. M., Magana-Arachchi, D. N., Chandrasekharan, N. V. \& Kulasooriya, S. A. (2014) Detection and quantification of cylindrospermopsin in water reservoirs of Sri Lanka using high performance liquid chromatography (HPLC) (2014) In: Illeperuma, O. A. et al. (eds) Symposium Proceedings, International Symposium on Water Quality and Human Health: Challenges Ahead, 27 - 28, June, PGIS, Peradeniya, Sri Lanka: p. 25.

Liyanage, H. M. \& Magana-Arachchi, D. N. (2012) Molecular identification of cylindrospermopsin producing Cylindrospermopsisraciborskii from Anuradhapura water reservoirs. In: Illeperuma, O. A. et al. (eds) Symposium Proceedings, International Symposium on Water Quality and Human Health: Challenges Ahead, 22 - 23, March PGIS, Peradeniya, Sri Lanka: p.14

Magana-Arachchi (2016) Toxicology of cyanobacteria.In: Illeperuma, O. A. et al (eds) Symposium Proceedings, International Symposium on Water Quality and Human
Health: Challenges Ahead, 05 \& 06 August, PGIS, Peradeniya, Sri Lanka: Invited speech xv.

Magana-Arachchi, D. N. \&Liyanage, H. M. (2012) Determining the presence of cyanotoxins in water reservoirs of Anuradhpura, using molecular and bioassay methods. Journal of the National Science Foundation, Sri Lanka, 40 (2): 157-167.

Melvani, K and Moles, J. A. (2013) Restoring riparian vegetation - A promising means to ensure clean water. In: Illeperuma, O. A. et al. (eds) Symposium Proceedings, International Symposium on Water Quality and Human Health: Challenges Ahead, 15-16, March, PGIS, Peradeniya, Sri Lanka: p. 30.

Perera, M. B. U., Yatigammana, S. K. \& Kulasooriya, S. A. (2012) Prevalence of toxigenic cyanobacteria in different climatic zones of Sri Lanka. In: Illeperuma, O. A. et al (eds) Symposium Proceedings, International Symposium on Water Quality and Human Health: Challenges Ahead, 22-23, March PGIS, Peradeniya, Sri Lanka: 31-32.

Perera, M. B. U., Yatigammana, S. A. Kulasooriya, S. A. \&Athukorale, N. P. (2013) Distribution of Cylindrospermopsisraciborskii (a toxin producing cyanobacterium) in freshwater reservoirs of Sri Lanka. In: Illeperuma, O. A. et al (eds) Symposium Proceedings, International Symposium on Water Quality and Human Health: Challenges Ahead, 15 - 16, March, PGIS, Peradeniya, Sri Lanka: p. 29.

Perera, M. B. U. and Yatigammana, S. K. (2014) Distribution and composition of cyanobacteria in Sri Lankan reservoirs In:Illeperuma, O. A. et al. (eds) Symposium Proceedings, International Symposium on Water Quality and Human Health: Challenges Ahead, 27 and 28 June, PGIS, Peradeniya, Sri Lanka: p14.

Piyasiri, S. (1995) Eutrophication and algae problem in Kothmale Reservoir, Sri Lanka. In: K. H. Timotius and Goltenboth (eds), Tropical Limnology |Vol 2, Safyas, Waccana University Press, Salatiga, Indonesia.

Rymuszka A. \&Sierosławska, A. (2009) (Review paper) Theimmunotoxic and nephrotoxic influence of cyanotoxins to vertebrates. Central European Journal of Immunology, 34 (2): 129136.

Seneviratne,G. and Kulasooriya, S. A. (2013) Reinstating sol microbial diversity in agroecosystems: The need of the hour for sustainability and health. Agriculture, Ecosystems and Environment 164: 181- 182.

Shihana, F., Jayasekera, J. M. K. B., Dissanayake, D. M., Ratnayake, P., Wickremasinghe, W \& Radella, Y. A. (2012) The short term effect of cyanobacterial toxin extracts on mice kidney. In: Illeperuma, O. A. et al (eds) Symposium Proceedings, International Symposium on Water 
Quality and Human Health: Challenges Ahead, 22- 23, March PGIS, Peradeniya, Sri Lanka: p.13.

Silva, D. B., and Manage, P. M. (2015) Removal of microcystin-LR from drinking water using natural rutile sand.In: Illeperuma, O. A. et al. (eds) Symposium Proceedings, International Symposium on Water Quality and Human Health: Challenges Ahead, 01 \& 02, August, PGIS, Peradeniya, Sri Lanka:

Silva, E. I. L. (2013) Species composition and relative dominance of reservoir phytoplankton in Sri Lanka: Indicators of environmental quality. In: Illeperuma, O. A. et al. (eds) Symposium Proceedings, International Symposium on Water Quality and Human Health: Challenges Ahead, 15- 16, March, PGIS, Peradeniya, Sri Lanka:p. 26.

Silva, E. I. L., Rott, E., Thumpela, I., Athukorala, N. \& Silva, E. N. S. (2013) Species composition and relative dominance of reservoir phytoplankton in Sri Lanka: Indicators of Environmental quality. International Journal of Biological Sciences and Engineering, ISSN 0975-1519, 4, (04): 92-102. (indexed in Directory of open access journals DOAJ, USA).

Silva, E. I. L. (1998) The occurrence of cyanobacteria in Mahaweli reservoirs of Sri Lanka. In: Procsymp on Cyanobacterial Toxins, PGIS, University of Peradeniya, April 1998: 7P.

Silva, E.I.L. and Wijeyaratne, M.J.S. (1999) The occurrence of cyanobacteria in the reservoirs of the Mahaweli river basin in Sri Lanka. Sri Lanka Journal of Aquatic Sciences 4: 51-60.

Wanigatunga,R. P., Kulasooriya, S. A. \& MaganaArachchi, D. N. (2015) Removal of cyanobacterial cells and microcystin in water using extracts of Moringaoleifera seeds. In: Illeperuma, O. A., Priyantha, N., Yatigammana, S. K., Madawala, H. M. S. P., \&Wijesundera, S (eds) Symp Proc. $4^{\text {th }}$ International Symposium on Water Quality and Human Health: Challenges Ahead, $27 \& 28$, June, PGIS, University of Peradeniya.Weerakoon, A. A., Jayawardana, B. P. A., Padmasiri, J. P. and Kulasooriya, S. A. (1998) Comparison of Algal Populations of Tisawewa and Basawakulama tanks in Anuradhapura. In: Proceedings of the Symposium on Cyanobacterial Toxins, PGIS, University of Peradeniya, April 1998: 12p.

West and West (1902) III.A contribution to the Freshwater algae of Ceylon. Transactions of the Linnean Society, London, 6 (3): 123-152.

Yatigamamana (2013) Biomanipulation: A review of biological control measures in eutrophic waters and potential for water body management in Sri Lankan reservoirs. In: Illeperuma, O. A. et al. (eds) Symposium Proceedings, International Symposium on Water Quality and Human Health: Challenges Ahead, 15-16, March, PGIS, Peradeniya, Sri Lanka: p. 27. 